\title{
Social Exclusion of Deprived Groups on the Example of the European Union
}

\author{
${ }^{\mathbf{1} M a r i a}$ Yu. Eflova, ${ }^{2}$ Alfiya A. Akbasheva \\ ${ }^{1,2}$ Kazan Federal University, 18, Kremliovskaya Str., 420008, Kazan, The Russian Federation \\ Email:meflova@gmail.com, allysmile@yahoo.com
}

Received: 02 ${ }^{\text {nd }}$ November 2018, Accepted: $28^{\text {th }}$ November 2018, Published: $31^{\text {st }}$ December 2018

\begin{abstract}
This article discusses the social exclusion of deprived groups on the example of the countries of the European Union. It gives the statistical data of the analysis of indicators with the identification of the causes of social exclusion. The paper considers institutionalization of social exclusion in the structure of modern society in the context of the European social model. The problems of socialization and social deformation of individuals related to drug abuse, distancing the state from solving the problems at the stage of taking drugs and at the stage of remission are an important aspect of the study. In general, we can talk about a single model of exclusion of deviant groups from society. In turn, it is the application of an interdisciplinary analysis to the study of narcotism and the social exclusion of the users of narcotic drugs helps to present this model and to show the ways of its reconstruction in order to reduce public grievance, as well as to restore the identity of the drug abuser. The main theses of the work arising from the application of the theory of social exclusion to the study of socially excluded deprived groups - the drug users, can be developed and specified in further studies of groups that are excluded from society for health reasons. The results of this study contribute to the expansion of the scientific understanding of the processes of institutionalization of social exclusion, form the basis for a new theoretical and applied area of focus in the sociology of deviant behavior.
\end{abstract}

\section{Keywords}

Social Exclusion, Social Expulsion, Drug Addicts, Interaction of Man and Social System, The Structure of Society, The Structure of Social Identity, The Institutional Framework of Social Expulsion

\section{Introduction}

Social exclusion is a relatively new research framework that addresses the problems of poverty, discrimination, intolerance, stigmatization and the infringement of human rights.

Social expulsion implies the absence or denial of resources and rights in a number of communities, resulting in their inability to participate in society's life, which affects the quality of life of socially expelled people and negatively affects society on the whole.

The authorship of the concept of "social exclusion" or "social expulsion" is attributed to the Secretary of State of the French government, René Lenoir, and implies any deprivation hindering the full integration of a person into the system of social relations [13]. This category primarily includes people with mental retardation and physical disabilities, orphans, people with addictions, marginals, people living below the poverty line [23].

The principles of equality in Europe, as well as the increasing role of democratic values, leads to an increase in the interest of the social sciences in the study of national minorities and economically challenged strata. The rapid growth of such social groups and, consequently, the exacerbation of the problem of unequal rights and opportunities is promoted by frequent economic crises and intensive migration, which leads to rising unemployment rate, forcing some groups of the population to fall below the poverty line.

\section{Methods}

When working on this article, the authors used methods such as: the search and study of research literature; the study of publications of Internet sources on the problem under consideration, general scientific empirical methods, such as comparison, observation, analysis, and content analysis.

A significant contribution to the study of the functioning of social institutions in society was made by G. Spencer, E. Durkheim, T. Parsons, A. Grauchi, D. North. [4]

The works of M. Weber, L. Wittgenstein, M. Heidegger lay the foundations of the analysis of the practices of social exclusion. The following scholars made significant contributions to the understanding of social exclusion and the construction of the theory: R. Lenoir, G. Rogers, B. Jordan, A. de Haan, S. Maxwell, A. Pover, C. Gore, V. Wilson, R. Atkinson, J. Hoberft, M. Wolfe, S. Paugam, P. Abrahamson, P. Thousand [11]. A significant contribution to the understanding of social exclusion was made by Russian sociologists F.M. Borodkin, P.V. Romanov, E.R. YarskayaSmirnova, D.B. Mokhov, M.S. Astoants, N.E. Tikhonova. Russian sociologists: A.A. Balabanov, N.M. Davydova, L.N. Ovcharova pointed to the relationship between exclusion and poverty in relation to the conditions of Russia, other aspects of social exclusion were also covered in the works by scientists N. G. Chevtaeva, A. M. Yushin. Contribution to the rethinking of the structure of modern society was made by E. Giddens. P. Bourdieu, Z. Bauman, A. Touraine, D. Bell, U. Beck, M. Castells, and also by O.I. Shkaratan, V.V. Radaev, T.I. Zaslavskaya, to the study of the elements of the structure and structurization of society through the prism of the theory of social exclusion - by N.E. Tikhonova, A.V. Dmitriev [12]. 
Foreign and domestic sociologists conduct research on various aspects of drug addiction and narcotization: B. Day, A. Lindsmith, E. Schur; in Russian sociology, authoritative studies in the field of narcotization include works by Y. I. Gilinsky, Y.Y. Komlev, A.L. Salagaev, P.A. Meylakhs, E.L. Omelchenko, A.A. Gabiani, O.V. Borodkina, M. Kh. Gonopolsky, G.G. Vorobiev, Y. N. Ikonnikova, A.V. Dmitrieva, V.V. Afanasyev, L.Y. Keselman, M.G. Matskevich, N.A. Sirota [11].

\section{Results and Discussion}

The aspects of drug use, mainly concerning the problem areas and related to the state of social exclusion, and negatively affecting both the most excluded and the society on the whole, have been studied. At the same time, an analysis of the scientific literature has shown that there is a lack of a holistic view of the mechanisms for institutionalizing social exclusion / inclusion, a system of inclusion of socially excluded deviant groups and individuals into society has not been theoretically developed; there is no description of the scenarios of social exclusion of deprived groups; lack of a systematic analysis of social response strategies to the practices of social exclusion of deprived groups.

The existing approaches to the understanding of social exclusion show that the study of this problem is europeanized. In 1975, the European Economic Community (EEC) developed the programs of actions to combat poverty, and already in the 1980s a five-year program was adopted on the economic and social integration of socially disadvantaged groups into society. In accordance with the Treaty on the Functioning of the EU, the Member States and the European Union are working together on the task of reducing poverty and marginalization of Europeans, improving the level and quality of life, and developing human potential. The European Commission contributes to the cooperation of countries, provides information and analytical support, conducts research, develops common initiatives, benchmarks and indicators, together with the Economic and Social Committee provides the necessary advice and gives opinions. In December 2010, the European Platform against Poverty and Social Exclusion was adopted. Under this platform, the European Commission mobilizes efforts in all policy areas to achieve the objectives set by the Europe 2020 program in this area [2].

The adoption of these measures was a reaction to the fact that in 2009 poverty was an acute problem for European society: about a quarter of the EU population lived below the poverty line. 2010 was declared the European Year for Combating Poverty and Social Exclusion. The initiative was aimed at mobilizing joint efforts of citizens, officials and social partners to combat poverty and social isolation, which has been affecting the most vulnerable groups of the population - young people, the elderly, unskilled workers, children from single-parent families, migrants. Employment problems that have exacerbated during the crisis period increase the growth of poverty and inequality. One tenth of the workers, mainly with low qualifications and temporarily employed, belongs to the category of the poor. Currently, there are 21,7 million unemployed people in the European Union - over 12 million of them have been unemployed for over a year, including 7 million - for more than two years; 14 million young people - 15-29 years old out of employment, education or training. Thus, at the present moment, poverty and inequality have increased and the European Union has put off the goal rather than approached it [2].

As a result of the growth of unemployment, the number of criminality and the growth of drug addiction increase. The socially excluded group of drug users is one of the most excluded among exclusive groups of society. For society, the issue of protection of rights and freedoms and inclusion of socially excluded groups is not a priority. Every person is endowed with natural rights from the moment of birth until the moment of death, human rights are inseparable from a person, and the possibility of their realization should be given to all people without exception. Responsibilities for the implementation and observance of human rights are assigned to government agencies that are the source, the author of institutionalized discriminatory scenarios.

A policy aimed primarily at combating drugs trafficking and ignoring the processes of recovery and inclusion of drug addicts is inhuman and runs counter to the legal and political trends and socio-political discourses of modern times. The effect of effectual policy is to reduce the level of drug use, as well as to realize the rights of socially excluded people, to low mortality rate and sufferings associated with the use of psychoactive substances. The theory of social exclusion is focused on practical activities in the field of social policy, analysis of interdisciplinary research on drug addiction and power scenarios through the prism of the theory of social exclusion, fixed at the level of normative legal acts, allows to determine the vectors of inclusion of deprived groups [14].

Use of narcotics and drug addiction are complex problems that have a unique history in various societies and specific theoretical research approaches in the sciences: sociology, medicine, economics, political science, psychology, law [15]. In sociology, narcotism and narcotization are the subject of study of the sociology of medicine and the sociology of deviance (deviantology). A separate scientific field of addictology has been formed - the sociology of addictions (alcoholic, narcotic, gambling, computer). Despite the fact that narcotism is a disease caused by the use of narcotic substances, it is primarily regarded as a form of deviant behavior. "The problem of inclusion / exclusion, first raised by French sociologists in the 60s-70s of the last century, has acquired particular importance for deviantology. The number of "excluded" (countries and groups of the population) from the active economic, political, social, cultural activities is getting greater, the gap between the "included" and "excluded" is getting wider [17].

Following the objectivist approach, narcotism (narcotization) is understood as a social problem and a form of deviant practices. Narcotism is the cause and effect of deviant behavior (delinquent nature) due to the use of prohibited psychoactive substances [24]. The objective and subjective nature of the existence of narcotism as a social problem is 
explained by the emergence of a negative social phenomenon as a result of the violation of generally accepted social norms and the reaction of society to this phenomenon.

Valuable experience regarding the deinstitutionalization of the deviation of drug users has been realized in England. A comparative analysis of the British medical approach and the American prohibitive approach in the field of drug policy to drug addiction was carried out by American sociologist, author of several works on deviant behavior, and an expert in the field of anesthesia, E. Shur. In general, based on the results of the analysis, the conclusions about the ineffectiveness of American drug policy in comparison with English one have been drawn. Drug addicts were not considered to be criminals in England, which consequently did not provoke an increase in criminal penalties as a result of drug use, despite this there was a strict control and punishment for the distribution of drugs. The key aspect of drug policy was the social rehabilitation of drug addicts and the implementation of the concept of reducing harm from drugs [8].

According to the European Monitoring Center for Drugs and Drug Addiction (EMCDDA) annual report, more than 32 million people, or almost $10 \%$ of the adult population in the European Union and Norway, used drugs in 2008, according to the annual report Most drug users in Europe (22,5 million) ) preferred marijuana. Amphetamine and ecstasy were taken by 2 million and 2,5 million people. About 4 million people are addicted to cocaine. Opiates, mostly heroin were often used by 1,2 million to 1,5 million people. Economists study the economic losses of society from drug addiction, which are expressed in reducing the amount of labor resources; the financial flows from the drug business that are unaccounted for by the state and the drug use market (supply and demand) are recorded. According to the World Drug Report 2014, "the overall situation with the prevalence of illicit drug use and problem drug use in the world remains generally stable, and the total number of drug users in the world increases in proportion to the growth of the global population" [9].

Within the framework of the cognitive approach, which has recently shown up wide range of application under the influence of the work of psychologists J. Piaget and A. Bandura, a low level of internal control is considered as the main reason that makes it difficult to quit using drug, and the violation of cognitive processes - as the main reason for the decline in social adaptability [17]. As part of the transactional analysis, the founder of which is E. Bern, normal personality development occurs with the coordinated interaction of an Adult, a Parent, a Child and in the event of intrapersonal conflicts a person is able to cope with them. A drug addict has one ego state dominating - the Child or an imbalance of Adult, Parent, Child occurs. On the other hand, drug addiction can be viewed as a game where an important part is played by co-dependents - the relatives of the addict who have no less imbalance in the psyche than the drug user has, and sometimes they do not allow the drug user to cease to play the role of the drug addict [18]. Thus, drug addiction is a family problem, as indicated by the representatives of the systems approach in psychology. It is important to note that deviation is due to the problems localized mainly not in the present, but in the past; and the channel of causality is often individualized and originates from the family.

\section{Summary}

Summing up the analysis of the problem of narcotization and narcotism within the scope of various sciences, we can note the complexity and multidimensionality of this phenomenon. Drug abuse undermines not only the physical health of the very consumer but also affects subsequent generations, and entails the possibility of contracting socially dangerous diseases that undermine the health of the nation (HIV, hepatitis $\mathrm{C}$, etc.). The consequence of narcotization is also an increase in the number of crimes and in the number of prisoners. However, a drug user, despite his social danger, is a sick person (both physically and mentally) and, in fact, his disease is a manifestation of the dysfunction of both small social groups and society on the whole.

No concept concerning the study of narcomania and narcotization is self-sufficient, they all complement each other, which gives grounds to apply interdisciplinary analysis. Social exclusion or social expulsion is a new concept developed at the interdisciplinary level, which involves intolerance, discrimination, exclusion, stigmatization, nonconformism [27]. The study of the social exclusion of drug users is, in fact, an analysis of the forms of borderline complex problems arising from the distribution and the use of psychoactive substances. Two opposite strategies to be considered in two approaches to the understanding of drug addiction "medical" and "criminal" have been conceptualized: a drug addict as a sick person and a drug addict as a criminal. Scientific concepts are closely interrelated with legal scenarios and institutionalize certain social practices in society. In turn, response strategies are built on their basis - either combating drugs, or adopting them and building an inclusive model [32]. Based on the scientific concepts, political and legal scenarios, social and cultural and moral scenarios are formed, which exerts influence on the process of institutionalization of social exclusion of drug addicts and forms the processes of institutionalization of subsequent inclusion.

\section{Conclusion}

Summarizing this work, the following conclusions can be drawn: The government plays the main role in the institutionalization of strategies. It is the government that not only selects those who are to be excluded but also prescribes its own forms of punishment for various types of exclusion - from medical intervention to where there is no disease to imprisonment where there is no crime" [29]. A sociological analysis of normative legal acts allows us to explore the peculiar issues associated with the institutionalization of the exclusion of drug users in certain cultural conditions and time frames. 
Social exclusion of drug addicts and drug users is formulated in the strategic principles of drug policy. The institutionalization process is laid at the macro level and manifests itself in the disruption of the functioning of the social system on the whole (systemic violations in the implementation of drug policies) and is fixed at the level of organizations in documents: legislative regulatory acts, instructions, prescriptions, etc. [4]. The impact of many social, economic, political, cultural factors reinforces or, on the contrary, weakens social exclusion in time and space. In turn, at the meso-level the exclusion is determined by the functioning of social institutions, the incompatibility of the regulatory legal framework with human rights, which has the effect of increasing harm from drugs, the unlawful situation in drug accounting, discriminatory scenarios in identifying drug users, inequality in receiving medical and social services by drug users, unbalanced allocation of budgetary resources between the state and public organizations aimed at social rehabilitation of drug addicts and imperfection of medical and rehabilitation procedures for drug users, enshrined in regulatory legal documents [28]. Discriminatory social practices that are common at the interpersonal level with regard to socially excluded groups reinforce the institutionalization of social exclusion and form psychological barriers and difficulties in finding employment both at the stage of the disease (use) and at the stage of rehabilitation.

\section{Acknowledgements}

This publication was prepared under the Jean Monnet Centre of Excellence in European Studies VOICES+ co-funded by the Erasmus+ Program of the European Union. This publication reflects the views only of the authors, and the Commission cannot be held responsible for any use which may be made of the information contained therein.

\section{References}

[1] Abrahamson, P. Postmodern Governing of Social Exclusion: Social Integration or Risk Management / P. Abrahamson // Sociologisk Rapportserie. -1998. - N 13.

[2] Barley, S.R., Tolbert, P.S. Institutionalization and structuration: Studying the links between action and institution. Retrieved [insert date] from Cornell University, ILR School site [Electronic Resource]. - Access Mode: http://digitalcommons.ilr.cornell.edu/articles/130/

[3] Battilana, J., Silvia D. Building Sustainable Hybrid Organizations: The Case of Commercial Microfinance Organizations / J. Battilana, D. Silvia //Academy of Management Journal. - 2010. - N 53. - P. 1419-1440.

[4] Mestrovic, S. Anthony Giddens: The Last Modernist / S. Mestrovic. — New York: Routledge, 1998. — P. 47.

[5]. Cohen, I. Structuration theory and Social praxis // Social theory today / I. Cohen. - Cambridge, 1987.

[6]. Stephen, R. Barley, Pamela, S. Tolbert Institutionalization and Structuration: Studying the Links between Action and Institution / B. Stephen, S. Pamela // Organization Studies January. - 1997. - N.18. - P. 93-117.

[7]. Battilana, J. Agency and Institutions: The Enabling Role of Individuals' Social Position // Organization. - 2006. - №13. - P. 653-676.

[8]. Munck, R. Globalization and Social Exclusion: A Transformationalist Perspective. - Bloomfield, CT, USA: Kumarian Press, Incorporated, 2004. - P. 21.

[9]. Rajendra, P. Understanding Social Exclusion and Social Inclusion in the Nepalese Context: Some Preliminary Remarks / P. Rajendra. - Kathmandu, 2006.

[10]. de Haan, A., Maxwell, S. Poverty and Social Exclusion in North and South / A. de Haan, S. Maxwell // IDS Bulletin. - 1998. - N. 29 (1). - P.1-9. [Электронный pecypc]. - Режим доступа: http://onlinelibrary.wiley.com/journal/10.1111/(ISSN)1759-5436.

[11]. Welshman, J. Underclass: A History of the Excluded, 1880-2000 / J. Welshman. - London, GBR: Continuum International Publishing. - 2007. - P. 214.

[12]. Abrakhamson, P. Social exclusion and poverty / P. Abrakhamson // Social Sciences and Modernity. - 2001. №2. - P. 148-166.

[13]. Avramenko, B.S. Drug Addiction: A Global Response to a Global Challenge. Avramenko // International Life. — 1992. — №11-12. - P. 75-81.

[14]. Aliyev, V.M. The Identity of the Disturber and Drug Addiction / V.M. Aliyev - M.: RI MIA RF 1993. - 85 p. [15]. Aristotle. Politics / Aristotle // Aristotle. Works in 4 Volumes. (Philosophical Heritage) V. 4. — M., 1984.

[16]. Astoyants, M.S. Social Exclusion in Modern Russian Society: Sociocultural Analysis / M.S. Astoyants - Rostovon- the Don: IPO PI SFU,2007.

[17]. Berger P., Lukman T. Social Construction of Reality. Treatise on the Sociology of Knowledge. - M .: "Medium", 1995. - 323 p.

[18]. Best, J. Social Problems / J. Best // Social Problems. - 2008. - № 2. [Electronic resource]. - Access Mode: http://socprob.ru/2008/sotsialnyie-problemyi-best-dzh.html.

[19]. Bogdanov, V. Tapering the Dose. Viktor Ivanov: For the First Time in Russia, the Growth of Narcotism Has Been Stopped / V. Bogdanov // Russian Newspaper. — 2014. — № 6412. — June 26.

[20]. Borodkin, F.M. Overcoming Social Exclusion: New Approaches / F.M. Borodkin // Sociological Journal. 2000. — № 3/4. — P. 5-17.

[21]. Giddens, E. Paul, Patriarchy and the Development of Capitalism / E. Giddens // Sociological Studies.- 1992. № 7. - P. 135-140. 
[22]. Giddens, E. Stratification and Class Structure / E. Giddens // Sociological Studies.— 1992. — № 9. — P. 112123.

[23]. Giddens, E. Sociology / E. Giddens / Translated from English; Scientific Edition by V. A. Yadov; Editors L. S. Gurieva, L. N. Posilevich. - M .: Editorial URSS, 1999. - 703 p.

[23]. Gilinsky, Y. I. Forever Excluded [Electronic resource]. - Access Mode: http://www.iuaj.net/node/738.

[24]. Dmitriyeva, A.V. Drugs as a Structuring Factor in a Consumer Society (On the Example of Legal Discourse) / A.V. Dmitrieva // Journal of Sociology and Social Anthropology.- 2011. - №5. - P. 338-347.

[25]. Dubrovsky, R.G., Teplitsky, V.G. The Development and Evaluation of the Effectiveness of Targeted Anti-Drug Programs / R.G. Dubrovsky, V.G. Teplitsky // Narcology. - 2010. - № 1. - P. 30.

[26]. Durkheim, E. Sociology. Its Subject, Method, Purpose / E. Durkheim. - M .: Canon,1995. - 352 p.

[27]. Eflova, M. Y. Family in the Postmodern Era / M. Y. Eflova / The Proceedings of the All-Russian Scientific Conference "National Identity of Russia and the Demographic Crisis", Kazan. - 2008.

[28]. Eflova, M. Y. Social Exclusion of Socially Deprived Groups of the Population (By the Example of Drug Users and HIV-Infected) / M.Yu. Eflova. - Kazan: Kazan University. - 2012. - 164 p.

[29]. Eflova, M. Y. Social Exclusion in the Russian Society: Economic, Social and Legal Aspects of Research / M. Y. Eflova / Modern Science: Actual Problems and Development Prospects: Monograph. Book 2 / Ed. Prof. I.N. Titarenko. - Stavropol: The Center for Scientific Knowledge "Logos", 2012. - P. 54-79.

[30]. Eflova, M. Y. Tolerance and Intolerance of Believers in the Context of Sociocultural Changes / M. Y. Eflova / Ethnicity, Rligiosity and Migration in Modern Tatarstan. Edited by R. G. Minzaripov, S. A. Akhmetova, L. R. Nizamova. -Казань: Kazan University, 2013. - 268 p.

[31]. Ефлова, М.Ю., Рябова Н.Ю. Институт семьи сегодня / М.Ю. Ефлова, Н.Ю. Рябова. - Казань, Еflovа, M.Yu., Ryabova N.Yu. Family Institute Today / M.Yu. Eflova, N.Yu. Ryabov. - Kazan,2008. - 60 p.

[32]. Keselman, L., Matskevich, M. Social Space of Drug Addiction / L. Keselman, M. Matskevich. - SPb.,2001.

[33]. Lisovsky, V. T. Drug Addiction as a Social Problem: a Case Study / V.T. Lisovsky // Bulletin of St. Petersburg University. Series 6. Sociology and Political Science. Issue 3 - 1998. 